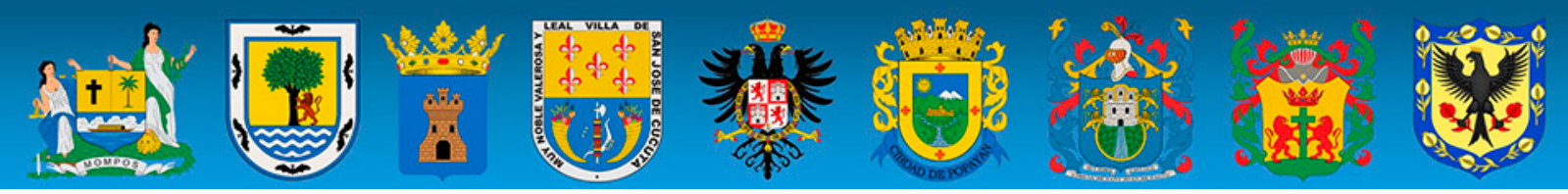

Artículo de reflexión E15A10. Recibido: 01.03.2019 * Aprobado versión final: 20.06.2019.

JEL: B15 - N16 - N46 - N96 * Pp. 85-97 doi:10.33571/teuken.v10n15a3

\title{
Una Nación extraviada en el tiempo. ¿Por qué 1819 y no 1810 como inicio de la Independencia?
}

\author{
A Nation lost in time. \\ Why 1819 and not 1810 as the beginng of Independence?
}

\author{
Juan Fernando Duarte Borrero \\ COLOMBIA
}

Resumen: 20 de julio de 1810 y 7 de agosto de 1819 son las fechas que tradicionalmente se han asociado con el momento preciso de la Independencia de Colombia. Pero al margen de los intereses políticos, es fundamental recurrir a la investigación reciente para pasar de largo de estas discusiones y remitirse a lo que la evidencia nos muestra. El presente artículo, concebido más como un ensayo que como un artículo de profundización, ofrece un panorama histórico acerca de las características que ofrecían los regímenes que identificaron al llamado Antiguo Régimen en lo que hoy es el territorio colombiano. Sin ninguna pretensión de novedad, esboza en unas páginas más de dos siglos de historia e invita a reflexionar sobre el origen de una nación que parece no haber nacido todavía.

Palabras clave: independencia de colombia; investigación histórica; revoluciones; historia económica; latinoamericanismo

Abstract: July 20, 1810 and August 7, 1819 are the dates that have traditionally been associated with the precise moment of Colombian Independence. But aside from political interests, it is fundamental to resort to recent research to pass through these discussions and refer to what the evidence shows us. This article, conceived more as an essay than as an in-depth article, offers a historical overview of the characteristics offered by the regimes that identified the so-called Old Regime in what is now the Colombian territory. Without any pretension of novelty, it outlines in a few pages more than two centuries of history and invites to reflect on the origin of a nation that seems not to have been born yet.

Keywords: independence of colombia; historical research; revolutions; economic research; latin-americanism

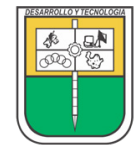

POLITÉCNICO COLOMBIANO JAIME ISAZA CADAVID
Juan Fernando Duarte es Historiador y Magister en Historia de la Universidad Industrial de Santander y Doctor en Historia por la Universidad Nacional de Colombia sede Medellín. Miembro del Grupo de Investigación Historia de las Representaciones, de la Escuela de Historia de la Universidad Industrial de Santander y profesor investigador en el Grupo de Investigación en Comunicación del Politécnico Colombiano Jaime Isaza Cadavid, en Medellín, Colombia.

Contacto: jfduarte@elpoli.edu.co 


\title{
Uma Nação perdeu no tempo.
}

\section{Por que 1819 e não 1810 como o começo da Independência?}

\begin{abstract}
Resumo: 20 de julho de 1810 e 7 de agosto de 1819 estas são datas que tradicionalmente se têm associado com o momento especial da Independência da Colômbia. Porém além dos interesses políticos, é fundamental observar a investigação recente para passar ao longo destas discussões e remitir-se ao que a evidência mostra. Este trabalho, concebido mais como um ensaio que como um artigo profundidade, oferece um panorama histórico sobre as características que ofereciam os regimes que identificaram ao chamado Antigo Regime no qual é hoje o território colombiano. Sem nenhuma pretensão de novidade, esboça em poucas páginas mais de dois séculos de história e convida a refletir sobre a origem de uma nação que parece não ter nascido ainda.
\end{abstract}

Palavras-chave: independência da colômbia; pesquisa histórica; revoluções; história econômica; latino-americanismo

"La Independencia sola, el gran clamor no acalla, si el sol alumbra a todos, justicia es Libertad!".

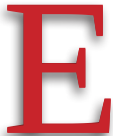

n el año 2010 el gobierno colombiano anunció "con bombos y platillos", como suele decirse, la celebración de los 200 años de vida independiente de Colombia y en este año que corre, el gobierno ha desarrollado un paquete de medidas para enmarcar la celebración de, otra vez, los 200 años de la independencia nacional. ¿Por qué esta ambigüedad? ¿Por qué dos fechas diferentes y por qué es motivo de discusión un evento tan importante, sobre el que debería existir consenso? La respuesta no es sencilla y esto obedece, en parte, a que los creadores de la forma republicana de gobierno se encargaron de "reconstruir" el pasado con el fin de que se acomodara a los objetivos políticos de entonces (Echeverri, 2018), esto es, los objetivos políticos del liberalismo del siglo XIX.

Lo que la investigación historiográfica más reciente nos permite afirmar, es que en lo que es hoy Colombia no hubo una guerra de independencia colonial, como sí la hubo en las colonias británicas de Norteamérica, ni existió un consenso amplio que impulsara la causa independentista. De hecho, muchos granadinos, léase "colombianos", al final del régimen español se sentían muy atados y genuinamente identificados con el régimen, con la figura del rey y con su aparato de gobierno. ¿Qué pasó, cómo llegamos a tener un consenso acerca de ser independientes? Al parecer, nunca existió tal consenso y fue la llamada "historia patria" la que desde el siglo XIX trató de enseñarnos eso. Y para entender cuáles fueron las circunstancias de la independencia alcanzada en 1819, es necesario hacer un rodeo. 
Durante el Antiguo Régimen, ese período que la historiografía tradicional nos enseñó a llamar "Época Colonial", el Virreinato del Nuevo Reino de Granada, que abarcaba aproximadamente las actuales repúblicas de Colombia, Venezuela, Ecuador, Panamá y parte de Costa Rica y Nicaragua, ${ }^{1}$ se había caracterizado por su relativa paz. Es decir, se caracterizó porque, en lo social y en lo político, no existieron manifestaciones significativas de resistencia al régimen virreinal o a la monarquía. ${ }^{2}$

Aunque es difícil explicar las razones de la relativa sumisión de estos territorios, es importante señalar que el territorio central del antiguo virreinato y que pasará a convertirse en la República de Colombia se caracterizó en su incipiente vida en libertad en el siglo XIX como uno de los países que más enfrentó trastornos civiles (Tirado, 1976). Y esto contrasta con el antiguo Virreinato de la Nueva Castilla, hoy República del Perú, que en tiempos del dominio español fue el protagonista de los levantamientos más populosos que enfrentó la Corona española en contra de su dominio y que, ya en el siglo XIX, tuvo una de las existencias más pacíficas entre los nuevos países de la región.

Los siglos del dominio español pueden dividirse en dos momentos. Momentos que coinciden casi exactamente con un poco más de un siglo de duración y con sendas dinastías que llevaron la corona en sus respetivos períodos. En el primero de ellos, la casa dinástica de los Habsburgo, antigua familia de origen austríaco, llevó a su máximo esplendor al imperio español al expandir su domino por cuatro continentes y convertirse en la primera potencia política y militar en Occidente (Thomas, 2018). Un predominio que, aunque duró poco, marcó un hito en la historia de la política internacional y definió el carácter de la colonización europea de América. El predominio español mantuvo a resguardo las llamadas Indias Occidentales del asedio de las demás potencias europeas, todas, al igual que España, ávidas tanto del oro y la plata como de los demás bienes que el Nuevo Mundo aportaba al incipiente capitalismo.

1 La gran extensión del Nuevo Reino de Granada contrasta con el actual territorio de la República de Colombia, pues a lo largo de los años el país fue cediendo grandes extensiones de tierra a todos sus vecinos hasta quedar en su estado actual. Sin embargo, la antigua delimitación sirve para explicar por qué el archipiélago de San Andrés y Providencia, tan cercano a las costas de Nicaragua, ha pertenecido siempre a Colombia, pues incluso buena parte del país centroamericano fue, en tiempos virreinales, parte de la Nueva Granada.

2 La única revuelta importante que existió en el Virreinato del Nuevo Reino de Granada fue la llamada "Revolución de los Comuneros" del Socorro (Santander, Colombia). Sigue siendo un libro imprescindible para entender este fenómeno, The People and the King: The Comunero Revolution in Colombia 1781, de John Phelan. 
Durante el tiempo en que reinaron los "Austrias", como pasaron a llamarse en España los representantes de la familia Habsburgo que ostentaron la corona entre 1516 y 1700, todos los dominios españoles en América tuvieron el mismo status que los dominios en Europa ${ }^{3}$. Al igual que Nápoles, Flandes y otros dominios del Viejo Continente, Méjico, Perú o el Nuevo Reino de Granada gozaron de igualdad de condiciones en el orden jurídico y administrativo. Los diferentes territorios de América, que los libros de texto escolares nos mostraban con colores diferentes y que ocupaban la mayor parte del continente, eran en realidad "reinos", no "colonias", lo cual le daba a estos territorios una condición diferente de, por ejemplo, los territorios controlados en América por Inglaterra o los Países Bajos.

A diferencia de estas potencias, España se interesó por la administración del territorio, pero también de todos sus ocupantes y eso implicaba la conversión de los nuevos súbditos a la religión del Estado por medio de la "cura" de sus almas (Muñoz, 2017). Fieles a la visión católica del mundo y de la vida en sociedad, de la cual no podía desprenderse como tampoco podía ponerse por encima de su propio tiempo, la Corona Española creó un Estado como hoy lo conocemos para poder hacerse cargo de la nueva tarea. Por su parte Inglaterra y Holanda veían a los nuevos territorios por ellos dominados como una fuente de ingresos a la par que enfrentaban situaciones muy diferentes desde el punto de vista religioso.

Amén de esto, España era la heredera de una tradición medieval en la administración política de sus territorios que era la herencia dejada por siglos de guerra con los españoles musulmanes. Una disputa conocida en la historia de ése país como la "Reconquista" que forjó cierto carácter de "guerra religiosa" a toda confrontación con enemigos no cristianos (Benassar, 1989). Por todo esto, España, o mejor, la Corona Española, tuvo el dilema de derrotar y controlar a sus nuevos súbditos con el compromiso de ganarlos para la fe cristiana católica y de convertirlos en vasallos leales, tratarlos como descarriados y con necesidad de ser corregidos, pero al mismo tiempo explotados. Y el dilema se solucionó con la creación de un aparato de Estado con funcionarios que vivieran para hacer posible la consolidación de un proyecto a medias político y a medias, religioso.

3 La vieja casa imperial de Austria llegó a reinar en España por cuenta del matrimonio del archiduque Felipe "El Hermoso" de Habsburgo (hijo del Emperador Maximiliano I de Austria y de María de Borgoña) con la infanta Juana (La Loca) de Castilla, hija y heredera de los Reyes Católicos Isabel I de Castilla y Fernando VII de Aragón. El primogénito de la joven pareja heredaría el trono de su madre como Carlos I de Castilla (España) y el de su abuelo austríaco, como Emperador Carlos V de Alemania, dando origen así a casi 200 años de presencia germánica en el trono de la península. 
Por supuesto, el costo de asumir este compromiso, fue elevado. El imperio de los Habsburgo fue un enorme territorio que, a lo largo de todo el siglo XVII funcionó produciendo cuantiosas pérdidas para la administración. Y fue tal la decadencia del espíritu de hidalguía que alguna vez estimulara la vida militar española, que esta forma de vida pasó a ser tema de no pocas obras literarias de esos días, incluyendo a Don Quijote, una obra fundacional que cuenta la historia de don Alonso de Quijano, un hidalgo que, enajenado con las historias de hidalgos y caballeros, encarna el alma perdida de una sociedad que se ha quedado atrás con respecto al pulso de la economía mundial que empezaba a surgir.

Esta debilidad económica del Imperio no implicó la debilidad política en los reinos de América. Para una organización política en la que la religión llevaba de la mano a los asuntos públicos, difícilmente la alcanzarían problemas de legitimidad o de puesta en duda del régimen. Ante cualquier evento que implicara una protesta, el grito de "Viva el Rey! Que muera el mal gobierno" denunciaba a las claras a quienes se le cargaba las tintas a la hora de señalar responsables. Hoy en día, cuando el gobierno es ejercido por un ciudadano más, nos resulta difícil entender el halo de inmunidad que rodeaba a la figura regia. Atreverse a hablar mal del Rey era similar a atreverse a hablar mal de Dios. En este orden e ideas, no es de sorprender que en este período hubieran existido en América tan pocas revueltas o intentos de insurrección. Y. si las hubo, en ningún caso tuvieron un programa independentista.

Pero esta realidad cambiaría en el siglo XVIII. Es un lugar común asociar el ambiente intelectual de este siglo, el Siglo de las Luces, con una de las llamadas "causas" de la independencia. Sin embargo, la moderna investigación nos ha mostrado que el modelo newtoniano de "causas y consecuencias" de muy poco sirve para entender los eventos de la historia. La Independencia, que fue un proceso iniciado al término de la primera década del siglo XIX tiene un profundo asidero en la situación interna del Imperio Español y los eventos ocurridos en el exterior fueron un detonante que no hubieran pasado de ser un proceso revulsivo, si las condiciones internas no hubieran estado dadas (Restrepo, 2019).

El siglo XVIII comenzó para todos los dominios de España con una nueva dinastía reinante, la Casa de Borbón. ${ }^{4}$ De origen francés, es decir,

4 Al morir sin descendencia Carlos II "El Hechizado", último de los Habsburgo de España, el rey Luis XIV de Francia impuso como candidato al trono español a su nieto Felipe de Borbón, duque de Anjou, quien era bisnieto de Felipe IV de España. Una vez proclamado en Versalles, el nuevo monarca asumió como Felipe $V$ y gobernó 45 años, el reinado más largo de la historia de España. Casi 320 años después, la dinastía Borbón sigue ostentando la corona española bajo el reinado de Felipe VI. 
proveniente del estado moderno más grande y centralizado de Europa, los nuevos ocupantes de la Corona Española estaban muy familiarizados con formas más eficientes de administración en la que el sistema de privilegios medievales, tales como las hidalguías y las prebendas no tenían ninguna consideración. De forma similar al funcionamiento de los modernos "paraísos fiscales", existían sectores de la sociedad privilegiados y exentos de impuestos y algunos miembros de la sociedad, de familias tradicionales, tenían un puesto ganado en la administración, sobre todo en el ejército, lo que no siempre era garantía de eficiencia en el servicio a la Corona.

Pues bien, los Borbón, en cabeza del rey Felipe V y sus sucesores, Fernando VI y Carlos III, iniciaron y ejecutaron un paquete de medidas que se conocen en la historia como las "Reformas Borbónicas" que tenían como único objetivo la modernización del Estado. El régimen que comenzó en 1701 y que se prolongaría hasta la segunda década del siglo XIX en América se caracterizó por el desmantelamiento de formas tradicionales de control en el que los títulos de nobleza comenzaron a dejar de ser una carta de presentación para ejercer ciertos cargos y se buscó la ayuda, el consejo y la participación de profesionales en áreas específicas. Aunque muchos de los nuevos funcionarios provenían de la nobleza, muchos otros venían del Común, ocasionando la primera de una larga seguidilla de molestias que le darán fama a este siglo.

Y existió un problema adicional. La familia Borbón había ascendido el trono español en 1701 con la profunda desconfianza del Imperio Austríaco, también candidato al trono por familia, ${ }^{5}$ y de Inglaterra y los Países Bajos, justificadamente celosos de que la misma familia controlase Francia y los inmensos territorios ultramarinos de España. El Tratado de 1713 logró, para los ingleses y potencias amigas suyas, que aunque quedara vacante el trono francés, nunca un Borbón español podría ocuparlo (Keuthe y Keneth, 2018). Esta y otras concesiones territoriales y comerciales tuvo que hacer España, consciente de la desventaja militar que tenía con respecto a Inglaterra, cuyo predominio en el mar no sería puesto en duda otra vez, sino hasta la Primera Guerra Mundial.

Con un Imperio amenazado, vigilado, en quiebra y con territorios ultramarinos constantemente amenazados por piratas que actuaban

5 Los Habsburgo pretendían retener el trono español con el pequeño príncipe austríaco José Fernando de Baviera, también bisnieto de Felipe IV de España. Lastimosamente el niño falleció a los siete años, en 1699, lo que favoreció los intereses de Luis XIV de Francia en favor de su nieto Felipe de Borbón, duque de Anjou. 
bajo la protección de Inglaterra, Francia y Holanda, España debió tomar cartas en el asunto. Su única fuente posible de ingresos era América que, hasta esa época, aportaba enormes cantidades de oro y plata que, en vista de los enormes compromisos españoles con la banca internacional, lo único que producían era fuga de capitales, inflación y, en últimas, una balanza de pagos deficitaria, como acertadamente lo han señalado los historiadores de la economía.

$Y$ es en esta coyuntura, en la que el sentido paternal que le inspiraba el rey de España a los súbditos de América y de buena parte de Europa, comienza a cambiar. La Corona era consciente de que lo único que hacía que los dominios de América no cayeran en manos de otras potencias era la distancia. Organizar una expedición armada de conquista de los territorios españoles de América por parte de Inglaterra era posible, aunque muy costoso y significaría una larga guerra de desgaste en la que los pocos destacamentos españoles podrían ser fácilmente derrotados, pero la ocupación del territorio era un problema diferente. Por esta razón, los ataques aislados y la toma de puertos importantes como Puerto Cabello, Maracaibo, La Habana o Cartagena de Indias, reportaban mejores dividendos.

Para hacer frente a una potencia que más que una amenaza, era un peligro real, España necesitó un plan de reformas económicas que tuvo profundas repercusiones en el ambiente espiritual de América (Lynch, 1991). Las Reformas Borbónicas implicaron la búsqueda de una mayor y mejor explotación de los recursos naturales disponibles, buscando fuentes de financiamiento diferentes a la volátil plata. Y este fue el origen de las reales expediciones botánicas, un proyecto a medio camino entre la ciencia y la economía, en el que se buscaba ubicar productos naturales susceptibles de ser comercializados bajo la forma de monopolio para así garantizar ingresos permanentes.

El producto de tales expediciones fue la adopción de un plan especial de rentas focalizada en productos tales como la quina, el añil y el tabaco. Todos eran productos de muy buena estima en los mercados internacionales y ofrecían la ventaja de obtener recursos permanentes en caso de necesitarlos para un posible enfrentamiento con Inglaterra. Y aunque dicha confrontación no pasó de ser más que una Guerra Fría, versión Siglo de las Luces, la preparación de España y sus dominios tuvo un efecto muy importante para la vida futura de América.

Con el objetivo de optimizar la explotación de estos recursos, la Corona transformó la enseñanza en el Nuevo Mundo. En contra de lo que nos ha hecho creer una parte de la historiografía tradicional, la mayor parte 
de las ideas nuevas de ese siglo, que serán calificadas más tarde como "revolucionarias", fueron traídas a España como vehículo necesario para el logro y la formación de los nuevos funcionarios. En los Colegios Mayores y Reales, léase Universidades, del Nuevo Mundo, se implementaron cátedras nuevas como las de mineralogía, astronomía, matemáticas, cálculo y economía, como un insumo intelectual necesario para la reacomodación de España en el sistema de equilibrio mundial que se presentaba.

Desde el punto de vista militar, las pocas fuerzas que existían en el Nuevo Mundo estaban concentradas en lugares neurálgicos para la economía de la Corona, como era el caso de Cartagena de Indias, en lo que hoy es Colombia (Keuthe, 1993), Veracruz en Méjico, o La Habana, en Cuba. Sin embargo, como ya se dijo antes, la distancia de los territorios en América constituía una defensa natural para ellas, por lo que la preocupación principal para España era la defensa de los territorios en Europa, toda vez que Inglaterra había tomado estratégicamente el peñón de Gibraltar, la puerta de entrada al Mediterráneo, que aún permanece en manos británicas.

En el territorio de lo que hoy es Colombia, la única revuelta importante en contra del gobierno español en esa época fue la del Socorro en 1781. Esta ciudad, capital de una populosa provincia del Nuevo Reino tenía como eje principal de su actividad económica el tabaco y, en vista de las nuevas regulaciones, se vio obligada a limitar su producción ocasionando la llamada Rebelión de los Comuneros. ${ }^{6}$ Un hecho aislado y enteramente excepcional que terminó con una petición pública de perdón del pueblo en pleno al rey, anécdota que los historiadores de la Independencia convenientemente ocultaron.

A pesar del afán modernizador de la Corona española y del logro parcial de algunas de las metas propuestas en el proceso, en realidad,

6 Como muchos otros procesos de rebelión popular, la Revolución de los Comuneros tuvo un claro móvil económico, motivado en la limitación al cultivo y producción de hoja de tabaco, la reinstauración del tributo de la Armada de Barlovento y otras cargas fiscales que asfixiaban a la población. La desigualdad económica mantenía privilegios para los españoles nativos, limitaba los derechos económicos de los criollos (hijos de españoles nacidos en América) y se ensañaba con los indígenas y los negros libertos. La rebelión fue detenida mediante las Capitulaciones de Zipaquirá, un acuerdo que revocaba las disposiciones tributarias, devolvía tierras arrebatadas a los indígenas, permitía el ascenso de los criollos a altos cargos públicos y otras reivindicaciones, pero luego el virrey invalidó el acuerdo, envió las tropas contra los Comuneros y ordenó el arresto de los líderes. José Antonio Galán y sus compañeros fueron ejecutados y descuartizados para escarmiento para sus seguidores. 
las nuevas medidas sirvieron como un incentivo al contrabando, tal vez la manifestación más importante de la Guerra Fría que anteriormente señalábamos. Con el contrabando, que muchos autores coinciden que se incrementó en las últimas dos décadas del siglo XVIII, muchos se enriquecieron. Tanto criollos como españoles nativos vieron en el comercio libre con los ingleses una fuente de lucro que el gravoso control de Madrid no permitía.

Muchos criollos vieron incrementado su nivel de vida, ya sea porque participaron directamente en el comercio ilícito, ya sea porque se beneficiaron indirectamente del aumento de la capacidad de compra de sus vecinos y familiares, que hacían sus transacciones por trueque o con oro en polvo, para evitar la vigilancia de los funcionarios reales. Aunque es imposible hacer extrapolaciones adecuadas y los contrafactuales poco tienen que ver con un tratamiento académico o científico, del pasado, en aras de ser lo más claro posible, esta situación se parece a la bonanza que en época reciente se vivió por el narcotráfico, en el que lograron beneficiarse sectores de la economía ajenos al ejercicio del mismo tráfico ilícito.

De esta forma llega la coyuntura de 1808, en la que Napoleón, ansioso por obstruir la entrada de Inglaterra, ocupó España y Portugal y encarceló al rey de España. El resultado de esto en América fue un movimiento conocido como el "Juntismo", una especie de seguidilla de juramentos de fidelidad al rey Carlos IV y después a su hijo Fernando VII, entonces encarcelados en Bayona por orden de Napoleón. Dichos juramentos se hicieron a partir de la instalación de juntas de gobierno creadas por los Cabildos, léase concejos municipales, de varias ciudades de América Hispana, como una forma de rechazo a la invasión francesa y como voto de fidelidad a la Corona, representada ahora por la junta principal reunida en Cádiz.

La más famosa de estas juntas en lo que hoy es Colombia fue la de Santafé, proclamada el 20 de julio de 1810 y que la tradición transformó más tarde en el "Grito de Independencia". En realidad, si bien pudo haberse dado varios gritos en esa fecha, ninguno perseguía la independencia o la separación política de la Corona. ${ }^{7}$ Una cosa que tiende a olvidarse, o que convenientemente no se ha querido recordar nunca, es que los criollos y otros estamentos sociales de América eran súbditos que estaban en

7 Una muestra de la intención de la Nueva Granada de conservar el vínculo político con España es el hecho de que la Junta de Gobierno proclamada el 20 de julio de 1810, incluía como miembro al entonces virrey Antonio de Amar y Borbón, representante legítimo del rey Fernando VII en estas tierras. 
94 intIIT/

igualdad de condiciones frente a los súbditos de Europa por lo que no era necesaria una Independencia (Gutiérrez, 2016). Lo que se buscaba era gobernar autónomamente a nombre del rey, de la misma manera en la que en Canadá o Australia, el Jefe de Estado es la reina Isabel II, aunque sean esos países los que eligen a su Jefe de Gobierno nacional.

Con la derrota de Napoleón y la expulsión de los franceses de España, el rey Frenando VII regresó al país y retomó el control de manera absolutista. En este sentido, derogó la Constitución de Cádiz de 1812, que buscaba acercar la monarquía española al modelo inglés y ordenó la reconquista de los territorios ultramarinos que ya empezaban a dar muestras de independencia política real. En Colombia, el resultado fue el proceso militar conocido como "el régimen del terror", encabezado por el general Pablo Morillo, que derrotó a las fuerzas de los estados republicanos formados en el antiguo Nuevo Reino de Granada con jurisdicciones que se superponían. De ahí el sobrenombre que le diera Antonio Nariño de "Patria Boba". Y fue la derrota del Departamento de Cundinamarca y de las Provincias Unidas de la Nueva Granada, lo que precipita la auténtica guerra, que sí tendrá por objetivo la independencia política del país.

Fue la desmedida represión y la falta de tacto político del rey de España las que precipitaron el proceso militar de la independencia. Un proceso en el que los reinos más ricos se mantuvieron al margen, como fue el caso de la mayor parte de Méjico, Cuba y el Perú. Sólo en los reinos más pobres, con menor hidalguía y con mejores resultados en el contrabando con Inglaterra, los más beligerantes, estallaron guerras independentistas, como fue el caso de los actuales Colombia, Venezuela y Chile. 
Las constantes órdenes y contraórdenes en el mando español llevaron al traste con la campaña de reconquista. Las enviadas al mando militar en la actual Colombia evitaron que un general bien formado y entrenado como Calzada estuviera al mando del enfrentamiento contra Bolívar y en su lugar fuera encargada la difícil misión al joven inexperto Barreiro. Además de esto, los retrasos en los suministros para el sostenimiento de la Tercera División del ejército realista proveniente de Venezuela y los desmanes producidos por la tropa en varios pueblos de la actual Colombia, hizo que el apoyo popular a Bolívar creciera de forma incontenible (Gutiérrez, 2019).

La ocupación de un puente sobre el río Teatinos le hizo creer a los americanos que apoyaban al rey y que conformaban el ejército realista -porque ningún ejército español participó en esta guerra- que tenían una ventaja táctica. Con las primeras luces del día, la vanguardia patriota atacó a los realistas haciéndoles creer que eran el grueso del ejército independentista. Los realistas, extenuados por una marcha forzada desde Paipa, arremetieron contra el enemigo seguros de su ventaja, sin advertir que, hacia el mediodía, la reserva y la caballería de los patriotas atacaron produciendo un gran desorden entre las fuerzas de la Corona, que fueron abatidas. A diferencia del combate conocido como del "Pantano de Vargas" ocurrido el pasado 25 de julio, en esta batalla, la Batalla de Boyacá, no hubo duda sobre el vencedor.

Sin embargo, la derrota de los realistas no fue aplastante. Se estima que durante el combate, menos de cien hombres murieron en el bando realista y algo menos de veinte en el de los patriotas, pero la ausencia de un mando militar experto facilitó la desbandada de los realistas y la captura de su jefe. Y una vez llegada la noticia a Bogotá, el Virrey Sámano, temeroso de represalias, ya que era sabido que los patriotas fusilaban o acuchillaban sin fórmula de juicio a los del bando del rey, huyó de Santafé junto con sus allegados, llevándose consigo, además, varios baúles con las arcas de la ciudad.

La prueba de que el ejército realista no estaba aniquilado es que en su ruta hacia Cartagena, varios pueblos de la ribera del río Magdalena fueron asolados por la turba que huía en desorden (Del Castillo, 2018). Ante la falta de un mando profesional, el ejército realista no "volvió cara" al enemigo, como suele decirse y su derrota fue el abandono de sus posiciones. 1819 fue la realización de un proyecto construido sobre la marcha, no de un proyecto pensado con los años o planeado por una élite que buscaba reemplazar a la Corona española. La solución militar fue la única manera de poner coto a los desmanes de un imperio desesperado por afianzarse en una tierra que había dejado de ser sumisa y que consideraba al rey como al padre supremo de la Nación. 
Una vez consolidada la victoria por la vía militar, vendría la ardua tarea de organizar el nuevo estado independiente, y para tal efecto, Bolívar convocó en la ciudad venezolana de Angostura (hoy Ciudad Bolívar), el Congreso Constituyente de la gran república con la que siempre soñó. La República de Colombia que hoy celebramos nació en tierras venezolanas, integraba lo que hoy son los territorios de Venezuela, Colombia, Panamá y Ecuador, nombró presidente a Bolívar, quien pronto dejó el cargo en manos de Santander para emprender la campaña del Perú, y fijó su capital en una hermosa ciudad que nunca se construyó. Muy pronto estrenaría la deuda externa, contraída con Inglaterra para sufragar los primeros gastos de reconstrucción del país y no mucho más tarde aparecería también la corrupción administrativa, que a pesar de ser combatida entonces con expropiaciones, destierros y fusilamientos, hoy goza de perfecta salud y presagia larga vida.

En rigor histórico, la gesta militar conocida en la historia como la"Campaña Libertadora" fue la respuesta a la reconquista española de América y no la avanzada del proyecto que inspiró al Juntismo. Sus integrantes eran otros, las condiciones eran otras y las lecciones aprendidas por la reconquista harían del nuevo experimento político algo mucho menos democrático que el experimento que se llevó a cabo en lo que hoy es Colombia, entre 1810 y 1815.

\section{Referencias bibliográficas}

1. BENASSAR, Bartolomé (1989). Los cristianos de Alá, Bilbao: Nerea.

2. DEL CASTILLO, Lina (2018). La invención republicana del legado colonial. Ciencia, historia y geografía de la vanguardia política colombiana en el siglo XIX. Bogotá: Universidad de Los Andes - Banco de la República.

3. ECHEVERRI, Marcela, (2018). Esclavos e indígenas realistas en la Era de la Revolución. Reforma, revolución y realismo en los Andes septentrionales, 1780 1825. Bogotá: Universidad de Los Andes - Banco de la República.

4. GUTIÉRREZ A., Daniel (2016). La restauración en la Nueva Granada (1815-1819), Bogotá: Universidad Externado de Colombia.

5. GUTIÉRREZ A., Daniel, (2019). 1819. Bogotá: Universidad Externado de Colombia.

6. KEUTHE, Allan J. y KENETH, Andrien (2018). El mundo atlántico español durante el siglo XVIII. Guerra y reformas borbónicas 1713 - 1796, Bogotá: Universidad del Rosario.

7. KEUTHE, Allan J. (1993). Reforma militar y sociedad 1773 - 1808. Bogotá: Banco de la República.

8. LYNCH, John (1991). La España del siglo XVIII, Barcelona: Crítica. 
9. MUÑOZ M., Santiago (2017). Hablamos la misma lengua, Barcelona: Crítica.

10. PHELAN, John Ledy (1978). The People and the King:The Comunero Revolution in Colombia 1781, Madison: University of Wisconsin Press.

11. RESTREPO O., Margarita, Coord. (2019) Los efectos de las reformas borbónicas en el virreinato del Nuevo Reino de Granada, Bogotá: Universidad del Rosario.

12. THOMAS, Hugh (2018). El Imperio español. De Colón a Magallanes. Barcelona: Planeta.

13. TIRADO M., Álvaro (1976). Aspectos sociales de las guerras civiles en Colombia, Bogotá: Colcultura.

Para citar este artículo:
DUARTE, Juan Fernando (2019). Una Nación extraviada en el tiempo. ¿Porqué 1819 y no 1810 como inicio de la Independencia? Teuken Bidikay Vol. $10 \mathrm{~N}^{\circ} 15$ Pp. 85-97. Medellín: Politécnico Colombiano. doi:10.33571/teuken.v10n15a3
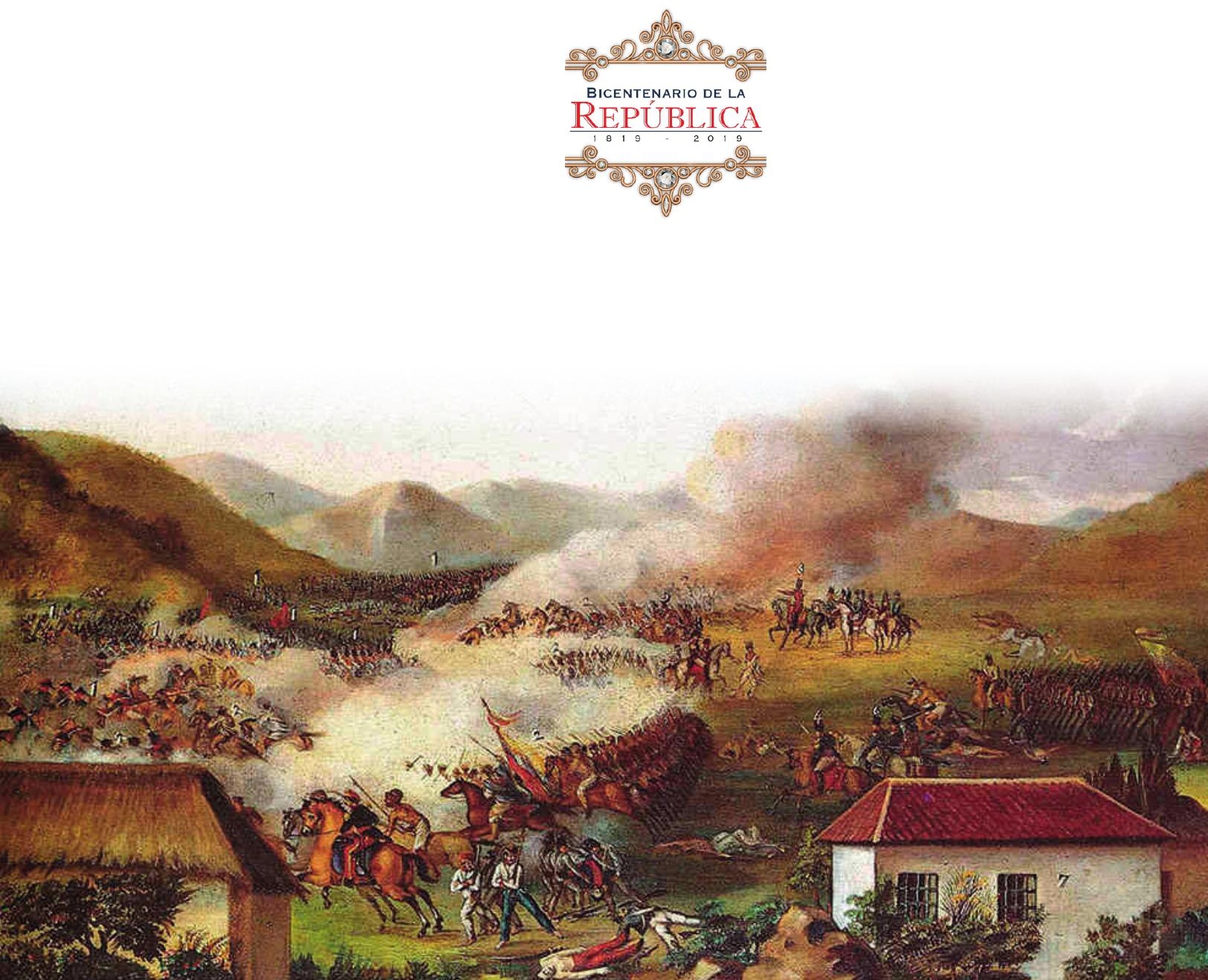
Declarada Monumento Nacional en 1975, la Casa de la Moneda es un lugar emblemático de la capital colombiana. Allí, en 1622, se acuñaron las primeras monedas de oro en América. La exhibición de una gran colección de billetes y monedas del Banco de la República, realizada en 1961, dio lugar a lo que hoy se conoce como el primer Museo Numismático. Este edificio colonial es, sin duda, un lugar que recoge la historia económica de Colombia, la cual ha estado permeada por los avatares de un sistema monetario capitalista que ha beneficiado la acumulación de riqueza en las élites políticas y las grandes corporaciones, a costa del empobrecimiento de las clases menos favorecidas. La distribución desequilibrada de la riqueza y las rentas ha abierto hondas brechas sociales, que sitúan a Colombia como uno de las sociedades más desiguales de la región y del mundo.

Laura Guzmán M.

Politécnico Colombiano.

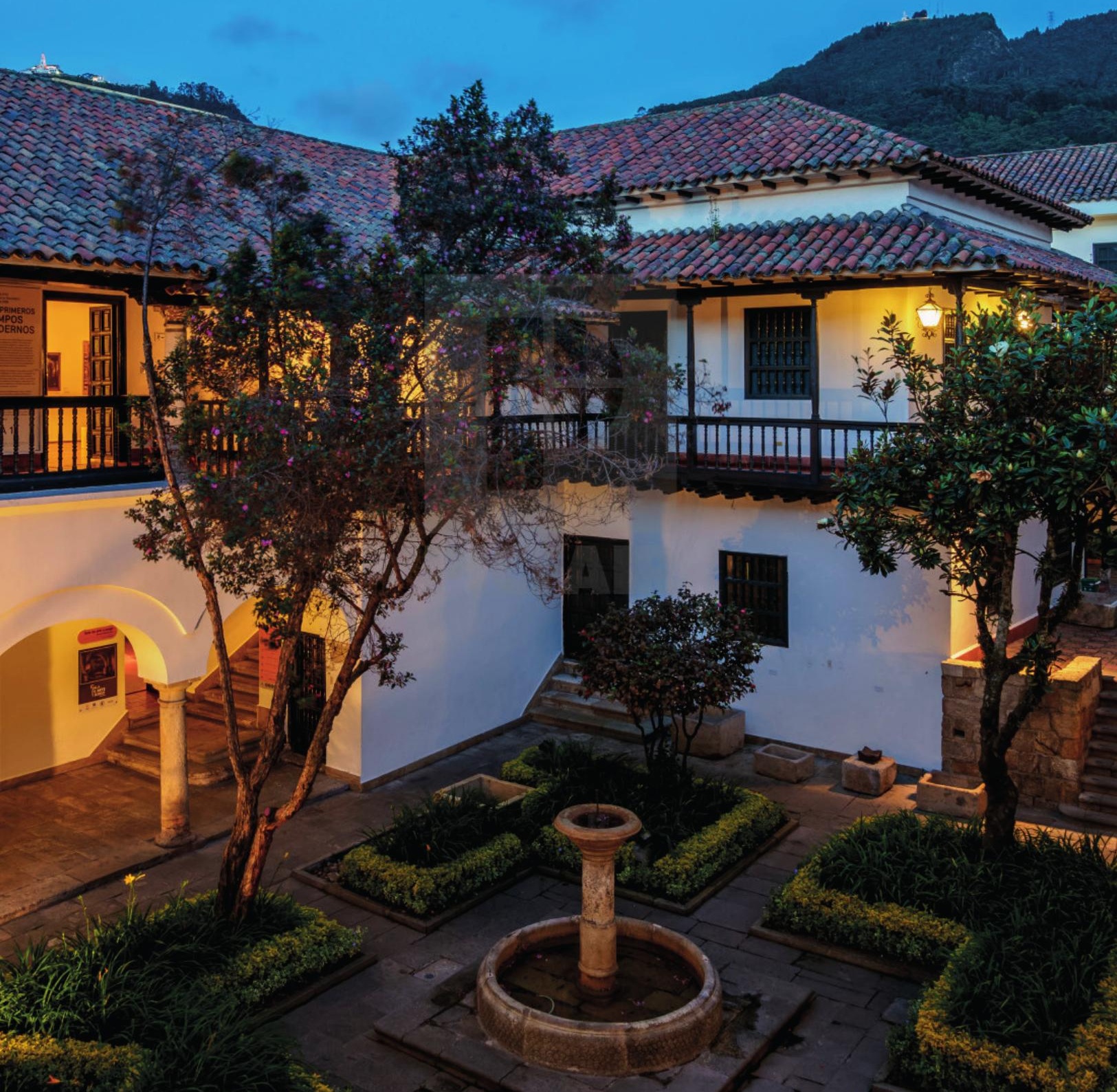

